\title{
Subclinical hypothyroidism in CKD patients in a population with a high prevalence of thyroid pathology
}

\author{
IRYNA GARMISHA-F, OLEKSANDER KURYATA ${ }^{\mathrm{A}, \mathrm{D}-\mathrm{F}}$ \\ ORCID ID: 0000-0002-0151-3065 ORCID ID: 0000-0001-7642-0077
}

Department of Internal Medicine 2 and Phthisiology, Dnipropetrovsk Medical Academy of Health Ministry of Ukraine, Dnipro, Ukraine

A - Study Design, B - Data Collection, C - Statistical Analysis, D - Data Interpretation, E - Manuscript Preparation, F- Literature Search, G - Funds Collection

Summary Background. Subclinical hypothyroidism (SCH) is established when serum thyroid-stimulating hormone (TSH) is above the defined upper limit and serum free thyroxine (FT4) is within the reference range. SCH is often not detected clinically, and its impact on kidney function is under active consideration, but not well established, despite the fact that hypothyroidism is associated with a negative effect on renal function. SCH may also be associated with low GFR.

Objectives. To evaluate the impact of thyroid disfunction on renal function in patients with subclinical hypothyroidism.

Material and methods. The study was conducted on the basis of one centre $(n=1,275)$, and the total sample was represented by patients with established CKD. After considering inclusion and exclusion criteria according to the Billewicz scale, determination of creatinine, TSH, T3 and T4 level, as well as estimation of GFR, was performed. Patients were then divided according to their TSH level. The results were analysed using Microsoft Excel, STATISTICA software and MedCalc.

Results. A direct relationship of TSH with creatinine $(\rho=0.49 ; p<0.001)$ and an inverse relationship with eGFR $(\rho=-0.49 ; p<0.001)$ were found. It was determined that TSH has a good prognostic ability for the prediction of kidney failure (AUC $=0.732 ; p<0.001$ ), and with a hormone level more than $3.51 \mu \mathrm{MO} / \mathrm{l}$, sensitivity will be $64.44 \%$ and specificity $-83.87 \%$.

Conclusions. The negative impact of TSH level on CKD progression already exists, while TSH only decreases to subclinical levels. Thus, $\mathrm{SCH}$ could be a significant risk factor for CKD.

Key words: hypothyroidism, glomerular filtration rate, renal insufficiency, chronic.

Garmish I, Kuryata O. Subclinical hypothyroidism in CKD patients in a population with a high prevalence of thyroid pathology. Fam Med Prim Care Rev 2020; 22(3): 202-207, doi: https://doi.org/10.5114/fmpcr.2020.98243.

\section{Background}

Subclinical hypothyroidism $(\mathrm{SCH})$ is defined as an elevated serum thyroid-stimulating hormone (TSH) above the defined upper limit of the reference range, with a serum free thyroxine (FT4) within the reference range [1, 2]. SCH cases present with few or no symptoms or signs of thyroid dysfunction, and thus, by its very nature, $\mathrm{SCH}$ is a laboratory diagnosis [3]. The prevalence of $\mathrm{SCH}$ in the United States in adults is 4-8.5\%; moreover, a European study has shown a higher prevalence of $\mathrm{SCH}$ among the female population $-10.8 \%$ [4]. There is paucity of such data in the Ukrainian population, despite the fact that thyroid pathology ranks first among all endocrinopathies in Ukraine (because of the delayed stochastic effects of the Chernobyl accident), and according to WHO, iodine deficiency - mild to moderate - has also been revealed throughout Ukraine [5]. Thus, there is no accurate data at present on the prevalence of SHS within the territory of Ukraine, but if we compare the prevalence of hypothyroidism in Europe and Ukraine, this is $0.2-2 \%$ and $4.1 \%$, respectively [6]. Due to its mostly asymptomatic nature, $\mathrm{SCH}$ cases are not detected clinically [2,3], and its relation to kidney function is also not well established.

Up to now, the association between $\mathrm{SCH}$ and the risk of some cardiovascular events has been established, but only in specific subgroups $[4,7]$. SCH has been identified as a strong predictor of mortality and a risk factor for cardiovascular disease in patients with chronic kidney disease (CKD) on haemodialysis $[4,8]$. However, the association between $\mathrm{SCH}$ with the risk of CKD is a matter of debate. The interaction between thyroid and kidney functions is well-known [9]. Thyroid hormones are involved in the growth, development and physiology of the kidneys $[2,9]$. The significant impact of hypothyroidism on biochemical parameters of renal function has been established - in comparison with euthyroidism, the level of serum creatinine is elevated, and glomerular filtration rate (GFR) values are reversibly reduced [2]. $\mathrm{SCH}$ also may be associated with low GFR. There is insufficient or no evidence to support an association between $\mathrm{SCH}$ and its systemic effects, in particular concerning the impact on renal function [1, 2].

The study was undertaken to evaluate the impact of subclinical hypothyroidism on renal function by estimating serum creatinine and estimated GFR (eGFR) in SCH patients.

\section{Material and methods}

With a view to explore the prevalence of thyroid disfunction, such as $\mathrm{SCH}$, we conducted the single-centre prospective study on the basis of the Centre of Nephrology Care in Dnipropetrovsk Mechnikov Regional Hospital, Dnipro, Ukraine. 1,275 patients were enrolled in our study. They had an established CKD diagnosis and needed the consultation of a nephrologist, according to the family doctor's appointment.

28 individuals taking TH replacement therapy and 145 taking medicines that can interfere with TSH measurement following the European Thyroid Association Guideline: Management of Subclinical Hypothyroidism were excluded [1]. Among the remaining patients, the Billewicz scale was applied (Figure 1) [10]. According to this scale, 981 patients were excluded from the study, because their Billewicz score was $<30$, which precludes both clinical and subclinical hypothyroidism. 


\begin{tabular}{|c|c|c|}
\hline & Present & Absent \\
\hline \multicolumn{3}{|c|}{ Symptoms } \\
\hline Diminished sweating & +6 & -2 \\
\hline Dry skin & +3 & -6 \\
\hline Cold intolerance & +4 & -5 \\
\hline Weight increase & +1 & -1 \\
\hline Constipation & +2 & -1 \\
\hline Hoarseness & +5 & -4 \\
\hline Deafness & +2 & 0 \\
\hline \multicolumn{3}{|c|}{ Signs } \\
\hline Slow movements & +11 & -3 \\
\hline Coarse skin & +7 & -7 \\
\hline Cold skin & +3 & -2 \\
\hline Periorbital puffiness & +4 & -6 \\
\hline Pulse rate & +4 & -4 \\
\hline Ankle jerk & +15 & -6 \\
\hline
\end{tabular}

Figure 1. Billewicz scale

Criteria for inclusion were: established CKD diagnosis; signed informed consent of the patient. Exclusion criteria: patients taking thyroid hormone replacement therapy and drugs that may affect the results of TSH level blood test; type 1 diabetes and type 2 diabetes insulin dependent; body mass index $>40 \mathrm{~kg} / \mathrm{m}^{2}$; hemodynamically significant cardiovascular diseases, arrhythmias and heart disease requiring medical or surgical treatment; acute myocardial infarction and acute cerebrovascular accident in up to 6 months; resistant arterial hypertension; severe decompensated heart failure of the III-IV functional class.

In all 121 patients, serum-free triiodothyronine (FT3), serum-free thyroxine (FT4) and thyroid stimulating hormone (TSH) concentrations were measured.

The examined patients were divided into 3 groups of observations depending on the TSH level:

- $\quad$ group 1 (control group) - TSH from 0.27 to $4.0 \mu \mathrm{MO} / \mathrm{I}$ (hormone values within normal range);

- $\quad$ group 2 (main group of observation) - TSH from 4.1 to $10.0 \mu \mathrm{MO} / \mathrm{I}$ (hormone values correspond to subclinical hypothyroidism);
- $\quad$ group 3 (comparison group) - TSH from 10.0 to 25.0 inclusive $\mu \mathrm{MO} / \mathrm{l}$ (hormone values correspond to hypothyroidism) (Table 1) (Figure 2).

After reviewing results of the Billewicz scale, 121 patients (12.3\%) had signs of thyroid disfunction, but after performing TSH level analysis - among 53 patients (43.8\%), thyroid disfunction was established: 8 patients $(6.6 \%)$ with hypothyroidism and 45 (37.2\%) with subclinical hypothyroidism. Hence, among all patients: eGFR is the preferred measurement of kidney function in the current study. This is estimated using the CKD-EPI formula.

Significant differences between the groups were found regarding the prevalence of stage 3 CKD in the 2 nd group ( $p=0.002$ ) (Figure 3).

All patients were examined and followed-up according to local and European standards, and all provided informed written consent on data collection. The study was approved by the Ethics Committee at the Dnipropetrovsk Mechnikov Regional Hospital (from 15.11.2016).

\begin{tabular}{|c|c|c|c|c|c|}
\hline Characteristics & All surveyed & Group 1 & Group 2 & Group 3 & $p$ between groups \\
\hline Number of patients, $n(\%)$ & $121(100.0 \%)$ & $68(56.2 \%)$ & 45 (37.19\%) & $8(6.61 \%)$ & - \\
\hline $\begin{array}{l}\text { Gender, } n(\%) \\
\text { women } \\
\text { men }\end{array}$ & $\begin{array}{l}97(80.17 \%) \\
24(19.83 \%)\end{array}$ & $\begin{array}{l}55(80.88 \%) \\
13(19.12 \%) \\
\end{array}$ & $\begin{array}{l}36(80.0 \%) \\
9(20.0 \%) \\
\end{array}$ & $\begin{array}{l}6(75.0 \%) \\
2(25.0 \%) \\
\end{array}$ & $p=0.925$ \\
\hline $\begin{array}{l}\text { Age, years } \\
\text { Me (25\%; } 75 \%)\end{array}$ & $58.0(48.0 ; 65.0)$ & $57.5(46.0 ; 63.0)$ & $60.0(50.0 ; 71.0)$ & $51.5(47.0 ; 66.0)$ & $p=0.277$ \\
\hline $\begin{array}{l}\text { Height, } m \\
\text { Me (25\%; 75\%) }\end{array}$ & $1.66(1.62 ; 1.70)$ & $1.66(1.62 ; 1.70)$ & $1.66(1.62 ; 1.70)$ & $1.65(1.59 ; 1.73)$ & $p=0.932$ \\
\hline $\begin{array}{l}\text { Body weight, kg } \\
\text { Me }(25 \% ; 75 \%)\end{array}$ & $80.0(69.0 ; 93.0)$ & $82.0(69.0 ; 92.5)$ & $76.0(68.0 ; 92.0)$ & $84.0(79.0 ; 96.5)$ & $p=0.215$ \\
\hline $\begin{array}{l}\text { BMI } \\
\text { Me (25\%; 75\%) }\end{array}$ & $29.38(25.39 ; 32.89)$ & $29.69(25.81 ; 33.40)$ & $27.25(23.63 ; 32.05)$ & $30.48(29.49 ; 31.27)$ & $p=0.182$ \\
\hline $\begin{array}{l}\text { Triiodo } \\
\text { thyronine, } \mathrm{mcg} / \mathrm{dl} \\
\text { Me (25\%; 75\%) }\end{array}$ & $4.26(3.28 ; 4.78)$ & $4.35(3.91 ; 4.8)$ & $3.21(3.01 ; 4.59)$ & $3.1(3.1 ; 3.5)$ & $\mathrm{p} 1-2=0.212$ \\
\hline $\begin{array}{l}\text { Thyroxine, } \mathrm{pg} / \mathrm{ml} \\
\text { Me (25\%; } 75 \%)\end{array}$ & $14.48(12.44 ; 17.12)$ & $14.64(13.14 ; 17.12)$ & $12.99(10.97 ; 17.22)$ & $12.1(11.18 ; 13.9)$ & $p=0.069$ \\
\hline $\begin{array}{l}\text { TSH, } \mu \mathrm{MO} / \mathrm{I} \\
\mathrm{Me}(25 \% ; 75 \%)\end{array}$ & $3.54(1.82 ; 5.3)$ & $2.1(1.38 ; 2.71)$ & $5.3(4.89 ; 6.5)$ & $18.21(13.55 ; 25)$ & $\begin{array}{l}p<0.001 \\
\mathrm{p} 1-2<0.001 \\
\mathrm{p} 1-3<0.001 \\
\mathrm{p} 2-3<0.001 \\
\end{array}$ \\
\hline $\begin{array}{l}\text { Daily proteinuria, g/day } \\
\text { Me }(25 \% ; 75 \%)\end{array}$ & $0.23(0 ; 1.5)$ & $0.09(0 ; 1.5)$ & $0.52(0 ; 2.2)$ & $0.18(0.03 ; 1.5)$ & $p=0.573$ \\
\hline
\end{tabular}




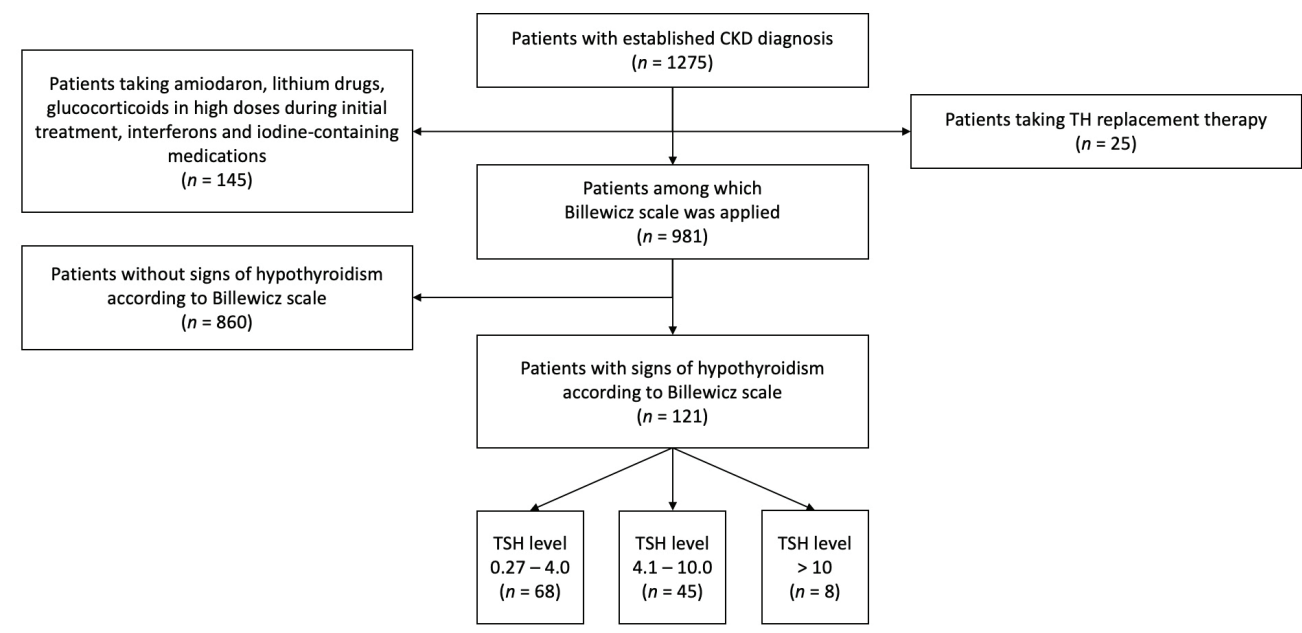

Figure 2. Study design

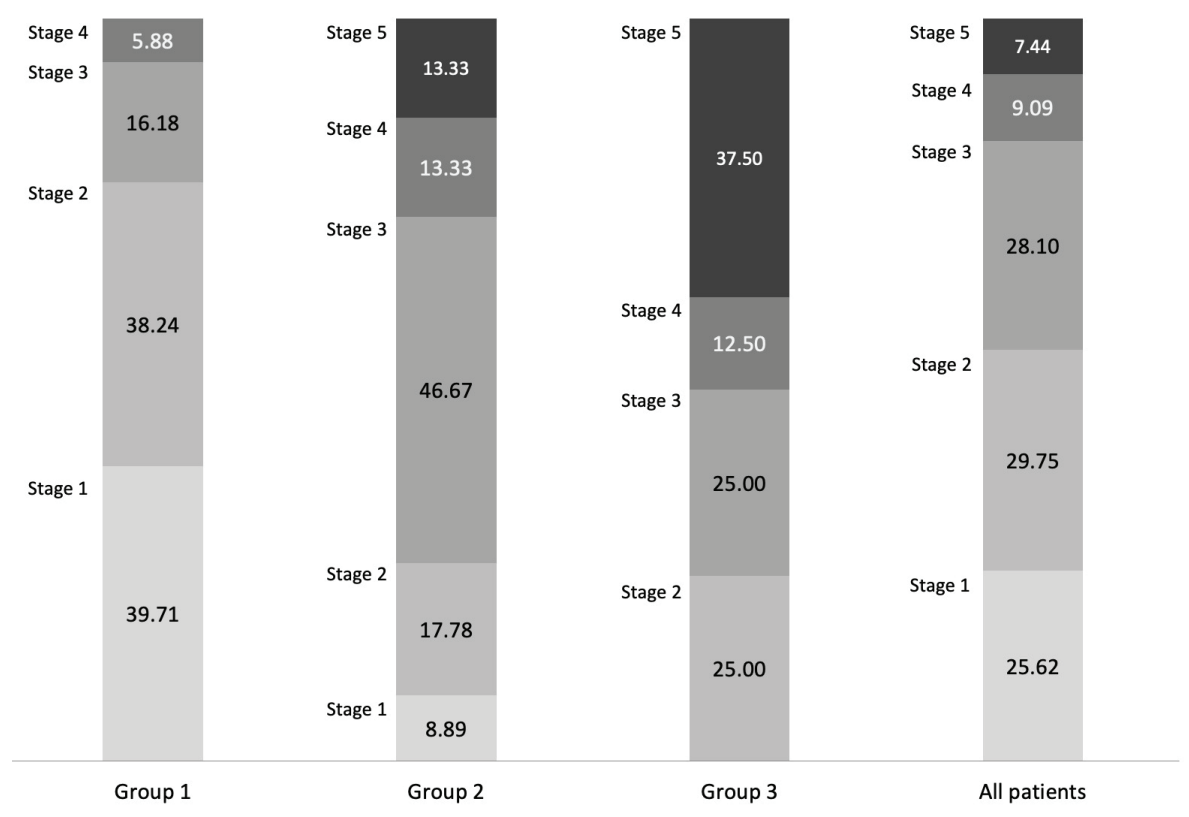

Figure 3. Characteristics of study groups by CKD stages (\%)

\section{Statistical methods}

Descriptive and analytical biostatistics were used for the statistical processing of the study materials. Median (Me) and interquartile range $(25 \%$; $75 \%)$ were used to describe the sample abnormal distribution of quantitative traits. Other statistical characteristics were also used: the number of observations $(n)$, relative values $(P), 95 \%$ confidence interval $(\mathrm{Cl})$, the level of statistical significance $(p)$.

The reliability of the difference of means for quantitative traits with abnormal distribution at multiple comparisons was carried out by nonparametric variance analysis. The likelihood of differences in categorical data was estimated by Pearson's chi-square test $\left(\chi^{2}\right)$. Spearman's rank $(\rho)$ was calculated for correlation analysis. ROC analysis was built on the values of the parameters of sensitivity (Se) and the specificity (SP) test and guidance with $95 \% \mathrm{Cl}$.

The critical value of statistical significance in the test of null hypotheses was assumed to be 0.05 (5\%).

Statistical processing of the results was performed using Microsoft Excel (Office Home Business 2KB4Y-6H9DB-BM47K749PV-PG3KT) and STATISTICA 6. 1 software (StatSoft Inc., Serial No. AGAR909E415822FA). ROC analysis and construction of ROC curves were performed in MedCalc Version 18.2.1, free trial version (MedCalc Software, Ostend, Belgium; https://www. medcalc.org/download.php;2018).

\section{Results}

The eGFR differed significantly between study groups $(p<0.001)$ and was highest in group 1 , in which it was 81.5 (66.16; 94.64) ml/min/1.73 $\mathrm{m}^{2}$, versus 44,87 (29.81; 60.99) $\mathrm{ml} / \mathrm{min} / 1.73 \mathrm{~m}^{2}$ in the 2 nd group and $28.46(10.64 ; 53.18) \mathrm{ml} /$ $\mathrm{min} / 1.73 \mathrm{~m}^{2}$ in the 3rd group (Figure 4).

The mean direct correlation was determined between TSH and stages of CKD in the 2nd group of the study, and among all those surveyed, the indicators are, accordingly, $\rho=0.40(p$ $<0.001$ ) for the 2 nd group and $\rho=0.48(p<0.001)$ for all patients.

In all subjects, and in the 2 nd group in particular, a direct relationship of TSH with creatinine $(\rho=0.42 ; p=0.005$ and $\rho=$ $0.49 ; p<0.001$, respectively) and an inverse relationship with eGFR ( $\rho=-0.45 ; p=0.002$ and $\rho=-0.49 ; p<0.001$, respectively) were revealed (Figures 5,6 ).

ROC analysis was performed to evaluate the potential of TSH for the prognosis of chronic renal failure. In order to do this, the examined patients were divided into groups: without renal failure $(n=39)$ and with renal failure $(n=90)$ (Table 2). 

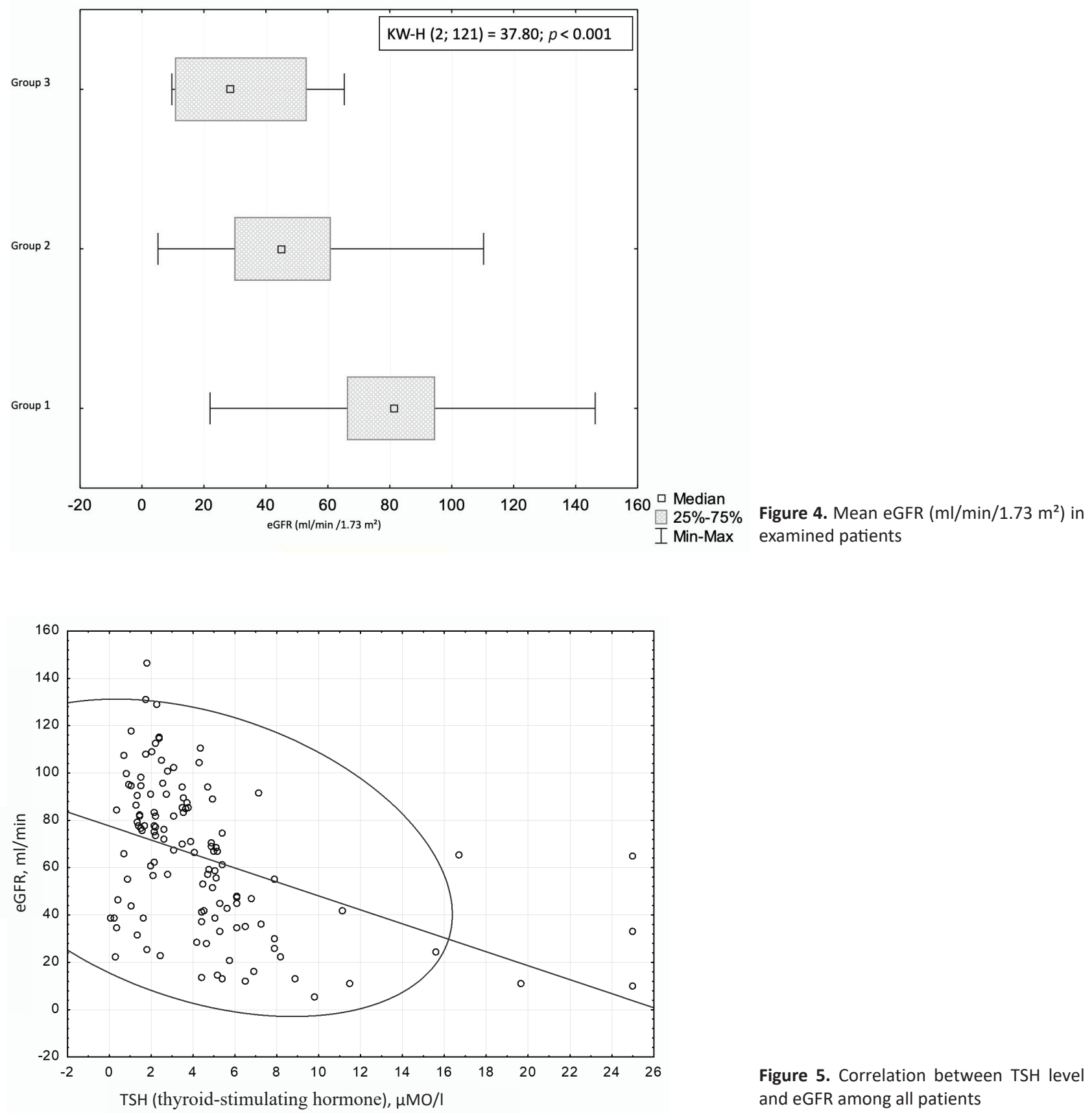

Figure 5. Correlation between TSH level and eGFR among all patients

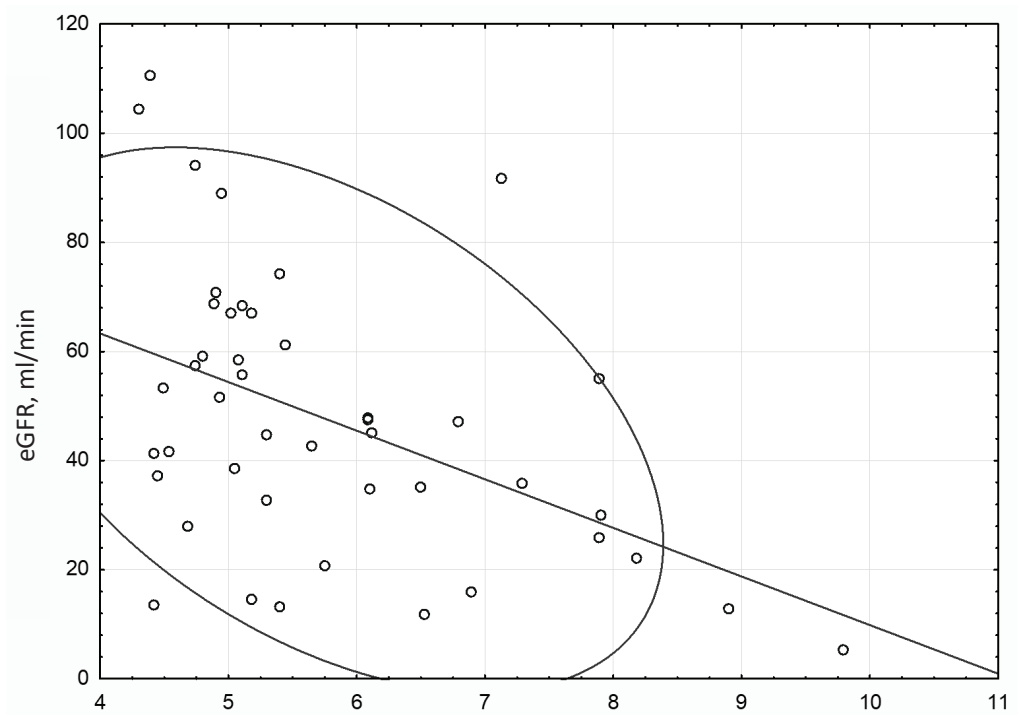

$\mathrm{TSH}$ (thyroid-stimulating hormone), $\mu \mathrm{MO} / \mathrm{l}$

Figure 6. Correlation between TSH level and eGFR in the 2 nd group 


\begin{tabular}{|l|l|l|l|l|l|l|}
\hline \multicolumn{2}{|l|}{ Table 2. Evaluation of the possibilities of using TSH as prediction of kidney failure (according to ROC analysis) } \\
\hline Indexes & AUC & $95 \%$ Cl AUC & $p$ & Se & Average & $\begin{array}{l}\text { Optimal cut-off } \\
\text { point }\end{array}$ \\
\hline TSH, $\mu \mathrm{MO} / \mathrm{L}$ & 0.732 & $0.644-0.808$ & $<0.001$ & 64.44 & 83.87 & $>3.51$ \\
\hline Triiodothyronine, $\mathrm{ng} / \mathrm{ml}$ & 0.664 & $0.453-0.835$ & 0.143 & 60.00 & 72.73 & $>4.27$ \\
\hline Thyroxine, $\mathrm{pg} / \mathrm{ml}$ & 0.643 & $0.496-0.772$ & 0.075 & 51.72 & 81.82 & $>15.68$ \\
\hline Age, years & 0.721 & $0.629-0.801$ & $<0.001$ & 50.57 & 88.46 & $>60$ \\
\hline
\end{tabular}

AUC - area under curve; Se - sensitivity; Sp - specificity.

The prognostic ability of TSH for the prediction of kidney failure can be estimated as good ( $A U C=0.732 ; p<0.001$ ), and with a hormone level more than $3.51 \mu \mathrm{MO} / \mathrm{l}$, sensitivity will be $64.44 \%$ and specificity $-83.87 \%$ (Figure 7 ). The prognostic ability of TSH is on the same level as age, which is a proven and significant factor of CKD progression.

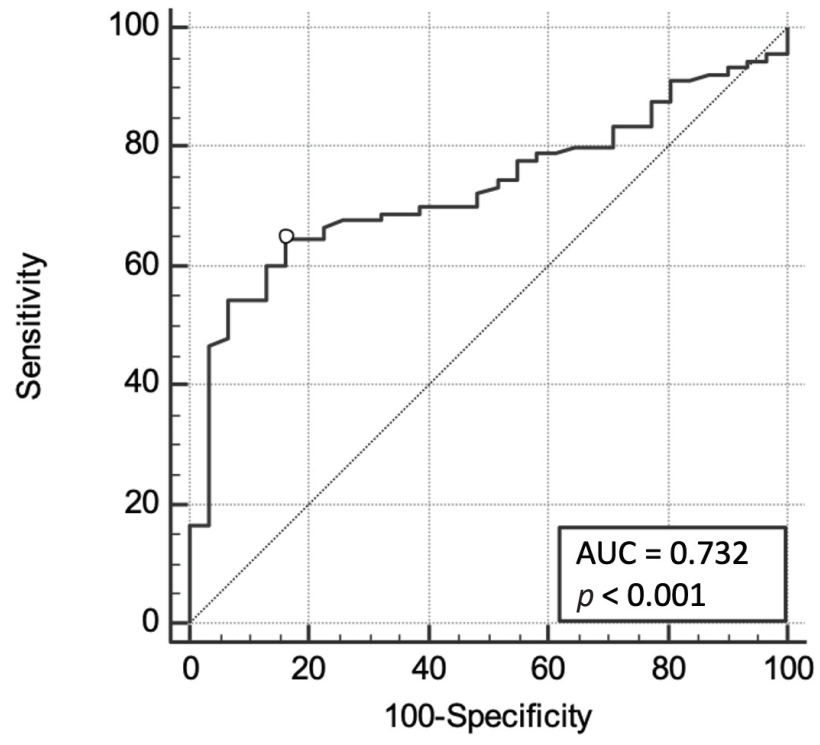

Figure 7. ROC curve for prediction of chronic renal failure based on determination of TSH

Logistic regression analysis showed that the TSH level is a significant independent factor of the development of chronic renal failure. An Odds ratio for TSH - OR $=1.439$ (95\% $\mathrm{Cl}$ : 1.099-1.885) shows that with every unit of increase in TSH, the chance of developing renal failure increases by 1.44 times (43.9\%).

\section{Discussion}

Today, if we are talking about CKD, then such causes as diabetes mellitus and arterial hypertension come first, but the pathology of the thyroid gland also has an effect on the development of this nosology. In particular, this factor may be significant for the Ukrainian region. However, there are no real statistics on the combination of kidney pathology and thyroid dysfunction, which determines the relevance of this study.

The average value of patients with thyroid disfunction in Europe is $3.7 \%$, while, according to our results, the proportion of these patients is $5.4 \%$. Moreover, when we use the Billewicz scale, it increases to $43.8 \%$, i.e. 8.1 times more than the initial ratio. It was also revealed that the percentage of patients with clinical hypothyroidism who, according to recommendations, require $\mathrm{TH}$ replacement therapy was $0.8 \%$ before using the scale, and after the survey it, was $6.6 \%$, which is 8.25 times higher. Thus, such a simple and available method for examination of patients as the Billewicz scale can significantly reduce the number of patients who require additional laboratory tests in order to determine the degree of functional disorders of the thyroid gland. Thus, the Billewicz scale can be the first step in a diagnostic search at the stage of visiting a general practitioner with a view to avoid excessive laboratory diagnostics.

Our research reported an association between $\mathrm{SCH}$ and CKD in hospital-based research. The present evidence suggested that $\mathrm{SCH}$ could be a significant risk factor for CKD. There is a linear trend present between TSH elevation and CKD moreover renal failure exists in this study. The exact mechanism by which high serum TSH leads to renal impairment remains unclear, which should prompt future studies.

It is necessary to take into account the fact that our study was conducted on the basis of only one centre, and it would be incorrect to extrapolate the results of this study to the entire population, since this geographical area refers to zones with iodine deficiency, which in turn can affect the prevalence of thyroid pathology.

The study involved patients who were treated in the Centre of Nephrology Care, and the results may possibly change if we add patients with early CKD who are under the supervision of family doctors.

\section{Conclusions}

1. TSH has direct correlation with stages of CKD in the 2nd group of study and among all those surveyed $-\rho=0.40$ for the 2 nd group and $\rho=0.48$ for all patients, with creatinine ( $\rho=0.42 ; \rho=0.49$, respectively), and there is an inverse correlation with eGFR $(\rho=-0.45 ; \rho=-0.49$, respectively). Thus, hypothyroidism without clinical manifestation (TSH up to $10.0 \mu \mathrm{MO} / \mathrm{I}$ ) can potentiate the progression of CKD. Moreover, patients in this group require more careful monitoring by the family doctor.

2. The increase of TSH level is associated with CKD progression: odds ratio for TSH - OR = 1.439 (95\% Cl: 1.099$-1.885)$; thus, the chance of developing renal failure increases by 1.44 times (43.9\%).

3. The Billewicz scale could be used by family doctors and internal medicine physicians as an initial survey method for patients with suspected thyroid disfunction.

Source of funding: This work was funded from the authors' own resources. Conflicts of interest: The authors declare no conflicts of interest.

\section{References}

1. Pearce S, Brabant G, Duntas L, et al. 2013 ETA Guideline: management of subclinical hypothyroidism. Eur Thyroid J 2013; 2(4): 215-228.

2. Patil V, Shilpasree A, Patil V, et al. Evaluation of renal function in subclinical hypothyroidism. J Lab Physicians 2018; 10(1): 50-55. 
3. Pertseva N, Einer K. Features of the influence of subclinical hypothyroidism on the cardiovascular system. Medicni perspektivi 2017; 22(4): 49-55.

4. Zhou J, Li H, Zhu X, et al. Subclinical hypothyroidism and the risk of chronic kidney disease in T2D subjects. Medicine 2017; 96(15): e6519.

5. Didushko O, Botsyurko N, Kostitska I, et al. Modern views on primary hypothyroidism in the light of conception of cardiovascular risk (literature review). Art of Medicine 2017; 3(3): 91-94.

6. Tkachenko $\mathrm{V}, \mathrm{Maksymets} \mathrm{Y}, \mathrm{Vydyborets} \mathrm{N}$, et al. Analysis of the prevalence and morbidity of thyroid pathology among the population of Kyiv region and Ukraine for 2007-2017. International Journal of Endocrinology (Ukraine) 2018; 14(3): 272-277.

7. Basu G, Mohapatra A. Interactions between thyroid disorders and kidney disease. Indian J Endocrinol Metab 2012; 16(2): 204-213, doi: $10.4103 / 2230-8210.93737$.

8. Kim EO, Lee IS, Choi YA, et al. Unresolved subclinical hypothyroidism is independently associated with progression of chronic kidney disease. Int J Med Sci 2014; 11(1): 52-59, doi: 10.7150/ijms.7186.

9. Alshammari F, Alhazaa S, Althemery A, et al. Prevalence of hypothyroidism among chronic kidney disease patients in security force hospital (SFH) in Saudi Arabia. J Family Med Prim Care 2019; 8(10): 3313-3317, doi: 10.4103/jfmpc.jfmpc_641_19.

10. Nazarpour S, Ramezani Tehrani F, Rahmati M, et al. Validation of Billewicz Scoring System for detection of overt hypothyroidism during pregnancy. Int J Endocrinol Metab 2018; 16(3): e64249, doi: 10.5812/ijem.64249.

Tables: 2

Figures: 7

References: 10

Received: 03.11.2019

Reviewed: 16.01 .2020

Accepted: 21.02 .2020

Address for correspondence:

Iryna Garmish, MD

Department of Internal Medicine 2 and Phthisiology

DSMA, Vernadsky Street 9

49044 Dnipro

Ukraine

Tel.: +380965459165

E-mail: garmish.ira@gmail.com 